\title{
Original Article Effective Control of Type 2 Diabetes through Antioxidant Defense by Edible Fruits of Diospyros peregrina
}

\author{
Saikat Dewanjee, Anup Maiti, Ranabir Sahu, Tarun K. Dua, and Vivekananda Mandal \\ Division of Pharmacognosy, Department of Pharmaceutical Technology, Jadavpur University, Kolkata 700032, India \\ Correspondence should be addressed to Saikat Dewanjee, s.dewanjee@yahoo.com
}

Received 25 November 2008; Accepted 28 May 2009

Copyright ( $) 2011$ Saikat Dewanjee et al. This is an open access article distributed under the Creative Commons Attribution License, which permits unrestricted use, distribution, and reproduction in any medium, provided the original work is properly cited.

\begin{abstract}
The matured fruits of Diospyros peregrina are successfully employed by the traditional healers and local people of costal West Bengal, India for the treatment of diabetes. Present investigation was undertaken to evaluate the role of hydroalcoholic extract of D. peregrina (HDP) on type 2 diabetes as well as the augmented oxidative stresses associated with it. Oral administration of HDP at 25,50 and $100 \mathrm{mg} \mathrm{kg}^{-1}$ body weight per day to diabetic rats was found to possess significant dose-dependent hypoglycemic and hypolipidemic activity. The diabetic rats showed lower activities of superoxide dismutase (SOD), catalase (CAT) and reduced glutathione (GSH) content in hepatic and renal tissues as compared to normal rats. The activities of SOD, CAT and GSH were found to be increased in extract-treated diabetic rats in selected tissues. The increased level of lipid peroxidation (thiobarbituric acid reactive substances) in diabetic rats was also found to be reverted back to near normal status in extract-treated groups. Thus it may be concluded that the HDP may produce its hypoglycemic effect through antioxidant defense mechanism.
\end{abstract}

\section{Introduction}

Diabetes mellitus is a chronic metabolic disorder characterized by elevated blood glucose concentration caused by insulin deficiency, often combined with insulin resistance [1]. By the year 2030, the total number of people worldwide with diabetes mellitus is projected to reach 366 million [2]. Type 2 or non-insulin-dependent diabetes mellitus (NIDDM) accounts for about $90 \%-95 \%$ of all diagnosed cases of diabetes [3]. Hyperglycemia alone does not cause diabetic complications. It is rather the detrimental effect of glucose toxicity due to chronic hyperglycemia mediated and complicated through augmented oxidative stress [4]. Hyperglycemia increases the production of reactive oxygen species (ROS) inside the aortic endothelial cells. ROSinduced activation of protein kinase-C isoforms, increased formation of glucose-derived advanced glycation end products, increased glucose flux through aldose reductase pathways and activation of cytokines are some of the known biochemical mechanisms of hyperglycemia-induced tissue and cell damage [5]. Thus, antioxidant therapy in diabetes may be helpful in relieving symptoms and complications observed in diabetes patients. Many traditional medicinal plants that possess substantial quantity of antioxidant components have been found to be useful against diabetes and its related complications $[6,7]$. Hence, there is a huge prospect of development of potential hypoglycemic agent coupled with antioxidant activity from traditional medicinal plants to combat diabetes and its complications [8].

Diospyros peregrina Gurke. (Ebenaceae) is a middlesized tree that grows luxuriantly in the plains of costal region in India. Mature fruits are edible with ethnomedicinal significance as tonic and aphrodisiace [9]. Unripe fruits are astringent, acrid, bitter and oleaginous [10]. Unripe fruits are used for the treatment of diarrhea, dysentery, cholera, mouth ulcer and in wounds [11]. The matured fruits of $D$. peregrina are successfully employed by the traditional healers and local people of costal West Bengal for the treatment of diabetes. The mature fruits of $D$. peregrina contain substantial quantity of phytopolyphenolics, which are known for their important antioxidant activity $[12,13]$. The present investigation was undertaken to evaluate the role of hydroalcoholic extract of $D$. peregrina fruit pulps (HDPs) in effective management of type 2 diabetes through antioxidant defense mechanism. 


\section{Methods}

2.1. Plant Material. Mature fruits of D. peregrina were collected in the month of July 2006 from the villages of costal West Bengal, India. The plant was authenticated by H. J. Chowdhury, Joint Director, Botanical Survey of India, Shibpur, Howrah, India. A voucher specimen $\mathrm{JU} / \mathrm{PT} / \mathrm{PC} / 01 / 06$ was deposited at our laboratory for future reference.

2.2. Chemicals. Streptozotocin was procured from SISCO Research Lab, Mumbai, India. Thiobarbituric acid was purchased from Loba Chemie, Mumbai, India. All chemicals and reagents used were of analytical grade.

2.3. Preparation of Extract. The fruit pulps were dried in an incubator at $40^{\circ} \mathrm{C}$ for 1 week, pulverized in an electrical grinder and macerated for $48 \mathrm{~h}$ at room temperature with $800 \mathrm{~mL}$ of mixture (double distilled water: 99\% absolute alcohol; $30 \%: 70 \% \mathrm{v} / \mathrm{v})$. The macerate was filtered and concentrated in vacuo (at $35^{\circ} \mathrm{C}$ and $0.8 \mathrm{MPa}$ ) and finally lyophilized to yield HDP $(7.5 \% \mathrm{w} / \mathrm{w})$. The total concentration of polyphenolics [14] and flavonoids [15] present in this extract was determined.

2.4. Animals. Three-day-old pups of the Wistar albino rats were used for this experiment. Pups were kept with the mother rat in a standard polypropylene cage. Animals were maintained under standard laboratory conditions of temperature $\left(20 \pm 2^{\circ} \mathrm{C}\right)$, relative humidity $(50 \pm 15 \%)$, $12 \mathrm{~h}$ lightdark cycle, standard diet and water ad libitum. The principles of Laboratory Animals Care [16] and the instructions given by our institutional animal ethical committee (Registration No: $0367 / 01 / \mathrm{C} / \mathrm{CPCSEA})$ were followed throughout the experiment.

2.5. Induction of Diabetes. The neonatal-streptozotocindiabetic rat model was performed as per the method described by Portha et al. [17]. Rats were injected intraperitoneally with $90 \mathrm{mg} \mathrm{kg}^{-1}$ streptozotocin in $0.01 \mathrm{M}$ citrate buffer ( $\mathrm{pH} 4.5)$ [17, 18]. Twelve weeks after the injection of streptozotocin, the animals exhibiting fasting glucose levels $140-200 \mathrm{mg} \mathrm{dL}^{-1}$ were screened as type 2 diabetic and neonatal-streptozotocin-diabetic rats resembling type 2 diabetes in humans [19].

2.6. Experimental Design. Animals were divided into six groups of six rats each. Group I: normal rats administered distilled water, $2.0 \mathrm{~mL} \mathrm{~kg}^{-1}$, orally daily for 5 days. Group II: diabetic control rats administered distilled water daily for 5 days. Group III: diabetic rats administered HDP, $25 \mathrm{mg} \mathrm{kg}^{-1}$, orally daily for 5 days. Group IV: diabetic rats administered HDP, $50 \mathrm{mg} \mathrm{kg}^{-1}$, orally daily for 5 days. Group $\mathrm{V}$ : diabetic rats administered HDP, $100 \mathrm{mg} \mathrm{kg}^{-1}$, orally daily for 5 days. Group VI: diabetic rats administered standard drug glibenclamide ( $1 \mathrm{mg} \mathrm{kg}^{-1}$, orally) daily for 5 days. Fasting blood glucose levels were estimated on Days 0, 1, 3, 5 with the help of single touch glucometer (Ascensia Entrust, Bayer Health Care, USA). Body weights of experimental rats

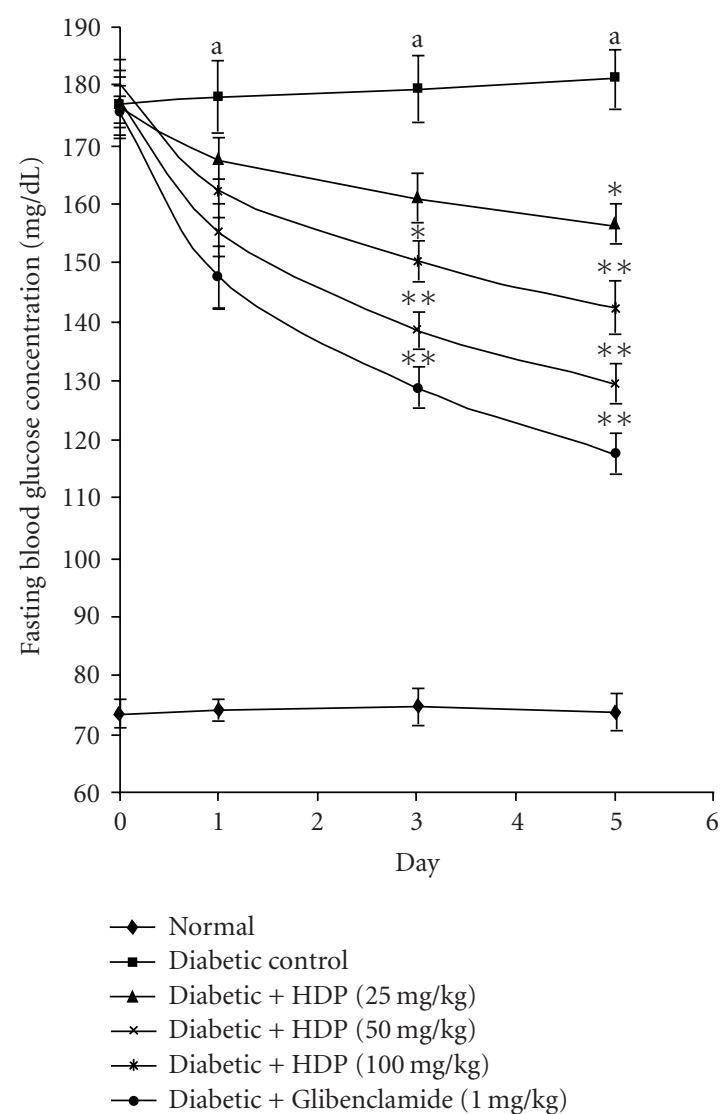

FIGURE 1: Effect of HDP on fasting plasma glucose level of neonatal-streptozotocin type 2 diabetic rats. Values are expressed as mean $+\operatorname{SEM}(n=6) .{ }^{a} P<.01$ compared with normal control group. ${ }^{*} P<.05$ compared with diabetic control group, ${ }^{* *} P<.01$ compared with diabetic control group.

were measured on Days 1, 3 and 5. After 5 days of treatment, all the rats were anaesthetized and sacrificed by cervical dislocation; livers and kidneys were excised and washed thoroughly to clear off blood. The tissues were immediately transferred to ice-cold saline and homogenized in $0.1 \mathrm{~N}$ Tris$\mathrm{HCl}$ buffer ( $\mathrm{pH}$ 7.4). These homogenate tissues were used for the estimation of thiobarbituric acid reactive substances (TBARSs) [20], reduced glutathione (GSH) [21], superoxide dismutase (SOD) [22] and catalase (CAT) [23]. Serum lipids and liver glycogen [24] profiles were also estimated.

2.7. Statistical Analysis. Data were statistically calculated by utilizing one-way ANOVA and expressed as mean \pm SEM. followed by Dunnett's $t$-test using computerized GraphPad InStat version 3.05, Graph pad software, USA. The values were considered significant when $P<.05$.

\section{Results}

3.1. Polyphenolics and Flavonoids Quantity. The level of total polyphenolic compounds was found to be $118.24 \mathrm{mg}$ of pyrocatechol equivalent per gram of dry weight of HDP. 
TABLE 1: Effect of HDP on serum lipids and liver glycogen levels of type 2 diabetic rats.

\begin{tabular}{|c|c|c|c|}
\hline Group & Cholesterol $\left(\mathrm{mg} \mathrm{dl}^{-1}\right)$ & Triglycerides $\left(\mathrm{mg} \mathrm{dl}^{-1}\right)$ & Liver glycogen $\left(\mathrm{mg} \mathrm{g}^{-1}\right)$ \\
\hline Normal control & $76.83 \pm 3.34$ & $78.83 \pm 3.12$ & $14.17 \pm 1.08$ \\
\hline Diabetic control & $111.17 \pm 4.64^{a}$ & $112.67 \pm 5.91^{a}$ & $7.45 \pm 0.69^{a}$ \\
\hline Diabetic + HDP $\left(25 \mathrm{mg} \mathrm{kg}^{-1}\right)$ & $91.54 \pm 6.12^{*}$ & $92.17 \pm 7.03^{*}$ & $12.38 \pm 1.01^{*}$ \\
\hline Diabetic + HDP (50 mg kg-1) & $89.24 \pm 4.22^{*}$ & $87.67 \pm 5.42^{*}$ & $13.35 \pm 1.21^{* *}$ \\
\hline Diabetic + HDP (100 mg kg-1) & $88.33 \pm 4.34^{* *}$ & $79.50 \pm 4.67^{* *}$ & $13.67 \pm 1.12^{* *}$ \\
\hline Diabetic + Glibenclamide $\left(1 \mathrm{mg} \mathrm{kg}^{-1}\right)$ & $89.67 \pm 3.62 *$ & $85.50 \pm 4.43^{* *}$ & $14.02 \pm 1.19^{* *}$ \\
\hline
\end{tabular}

Data are mean \pm SE of six animals for each group.

${ }^{a} P<.01$ compared with normal control group.

${ }^{*} P<.05,{ }^{* *} P<.01$ compared with diabetic control group.

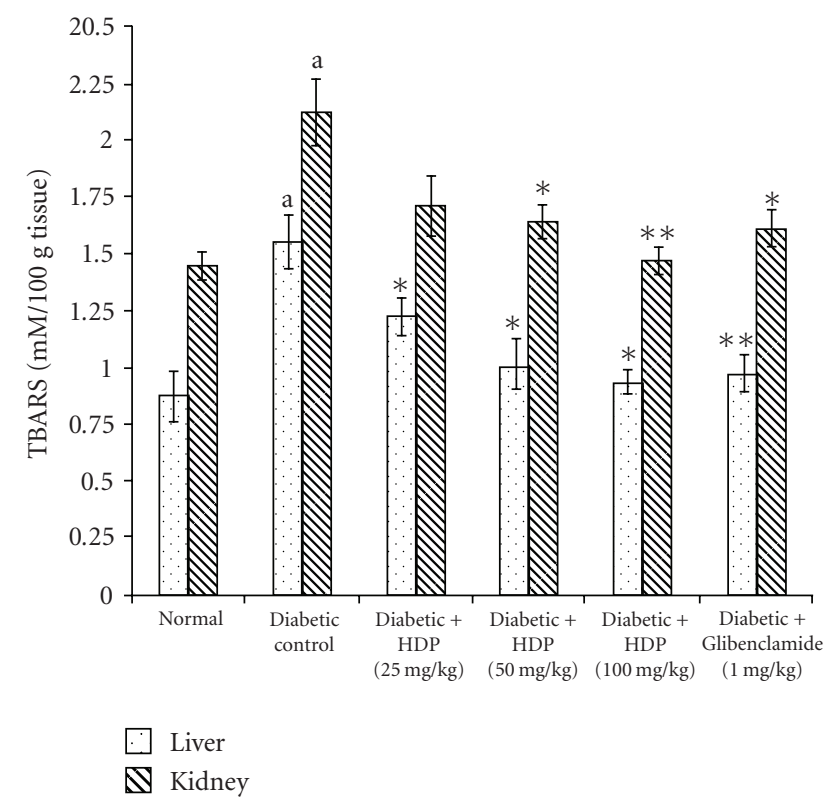

Figure 2: Effect of HDP on TBARS of hepatic and renal tissues of type 2 diabetic rats. Data are mean \pm SE of six animals for each group. ${ }^{a} P<.01$ compared with normal control group. ${ }^{*} P<.05$ compared with diabetic control group, ${ }^{* *} P<.01$ compared with diabetic control group.

Total flavonoids content was found to be $84.45 \mathrm{mg}$ of quercetin equivalent per gram of HDP.

3.2. Blood Glucose Status. A significant difference was observed between normal and type 2 diabetic rats $(P<.01)$ in fasting blood glucose level. HDP at the doses of 25,50 and $100 \mathrm{mg} \mathrm{kg}^{-1}$ body weight significantly lowered fasting blood glucose level of type 2 diabetic and exhibited maximum reduction of $13.98(P<.05), 23.89(P<.01)$ and $32.05 \%$ $(P<.01)$ on Day 5 , respectively. The results were compared with standard oral hypoglycemic agent glibenclamide $\left(1 \mathrm{mg} \mathrm{kg}^{-1}\right)$, which exhibited maximum reduction of $36.12 \%$ $(P<.01)$ on Day 5 (Figure 1 ).

3.3. Blood Lipid Status. Significant increase $(P<.01)$ in cholesterol and triglycerides levels was observed in diabetic rats when compared with normal control groups. Treatment

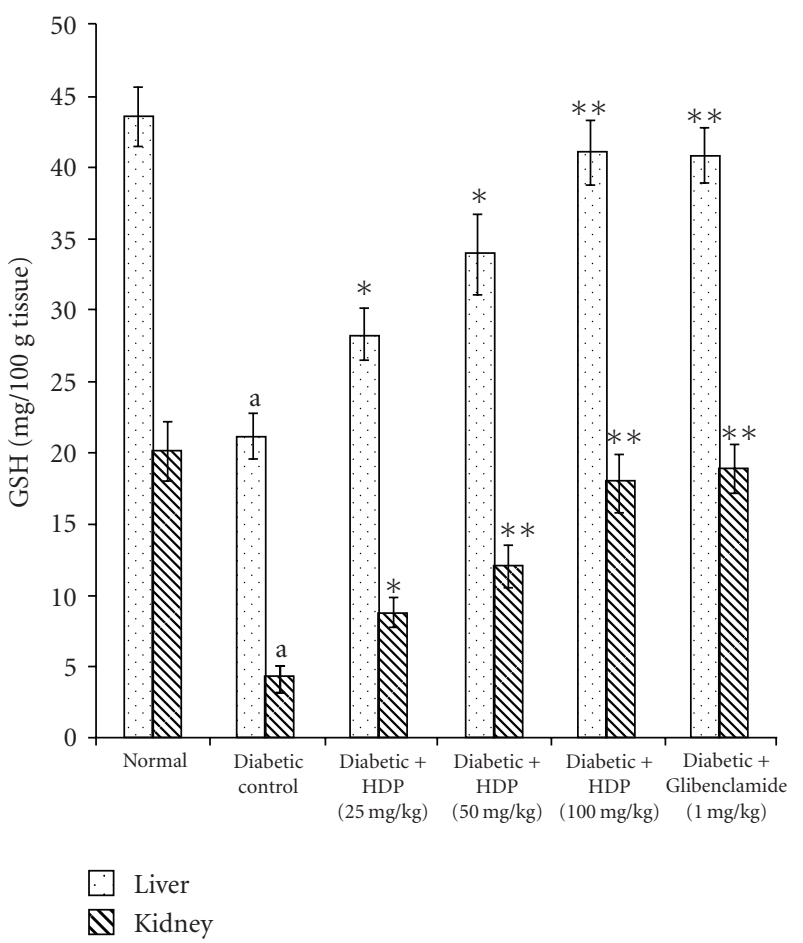

FIGURE 3: Effect of HDP on GSH of hepatic and renal tissues of type 2 diabetic rats. Data are mean \pm SE of six animals for each group. ${ }^{a} P$ $<.01$ compared with normal control group. ${ }^{*} P<.05$ compared with diabetic control group, ${ }^{* *} P<.01$ compared with diabetic control group.

with HDP significantly lowered the levels of cholesterol and triglyceride in a dose-dependent manner when compared with diabetic control group. The hypolipidemic effect is more at the dose of $100 \mathrm{mg} \mathrm{kg}^{-1}$ and results are comparable to that of standard drug glibenclamide. A significant decrease $(P<.01)$ in the level of liver glycogen was observed in diabetic rats when compared with normal control groups (Table 1).

3.4. Liver Glycogen and Body Weight Status. Oral administration of HDP at the selected doses significantly increases liver glycogen level to its normal level and the result is comparable to that of standard drug glibenclamide (Table 1). 
TABLE 2: Effect of HDP fruit on body weight profile of type 2 diabetic rats.

\begin{tabular}{lcrr}
\hline Group & \multicolumn{3}{c}{ Body weight profile $(\mathrm{g})$} \\
& Day 1 & Day 3 & $167.50 \pm 2.81$ \\
Normal control & $164.17 \pm 3.01$ & $135.83 \pm 4.36$ & $168.33 \pm 2.11$ \\
Diabetic control & $137.50 \pm 4.96$ & $143.33 \pm 2.79$ & $135.50 \pm 3.99$ \\
Diabetic + HDP $\left(25 \mathrm{mg} \mathrm{kg}^{-1}\right)$ & $142.5 \pm 3.09$ & $143.33 \pm 6.28$ & $144.17 \pm 2.82$ \\
Diabetic + HDP $\left(50 \mathrm{mg} \mathrm{kg}^{-1}\right)$ & $140.00 \pm 5.77$ & $140.83 \pm 4.55$ & $145.83 \pm 6.38$ \\
Diabetic + HDP $\left(100 \mathrm{mg} \mathrm{kg}^{-1}\right)$ & $141.67 \pm 4.60$ & $144.17 \pm 6.11$ & $139.50 \pm 5.05$ \\
Diabetic + Glibenclamide $\left(1 \mathrm{mg} \mathrm{kg}^{-1}\right)$ & $140.83 \pm 6.23$ & & $147.50 \pm 6.42$ \\
\hline
\end{tabular}

Data are mean \pm SE of six animals for each group.

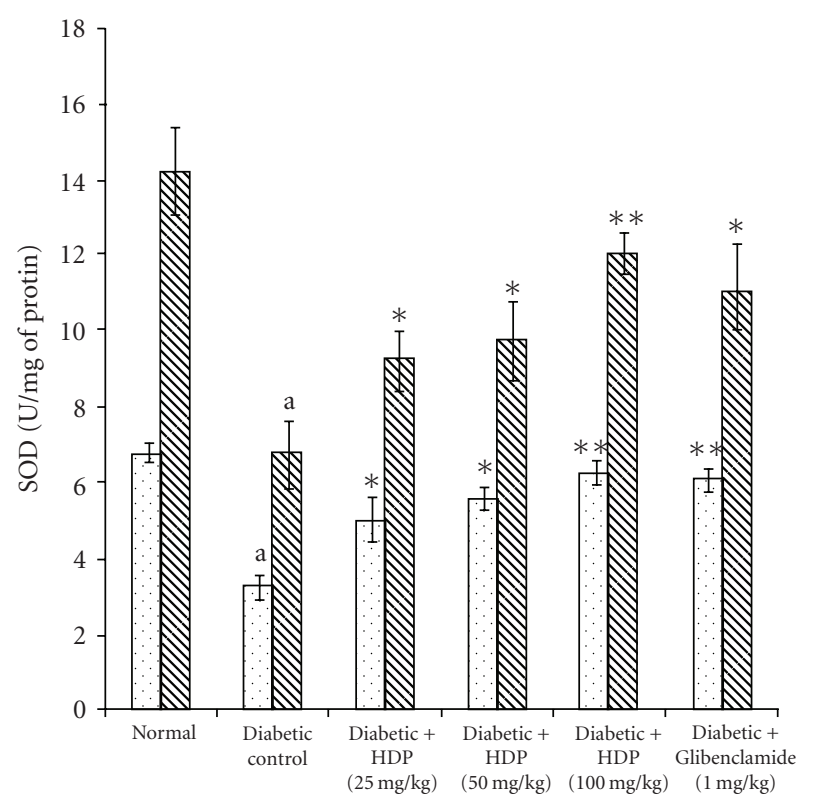

$\square$ Liver

N Kidney

FIGURE 4: Effect of HDP on SOD of hepatic and renal tissues of type 2 diabetic rats. Data are mean \pm SE of six animals for each group. ${ }^{\text {a }} P$ $<.01$ compared with normal control group. ${ }^{*} P<.05$ compared with diabetic control group, ${ }^{* *} P<.01$ compared with diabetic control group.

HDP treatment also improved body weight profile (statistically insignificant) in type 2 diabetic rats with respect to diabetic control group (Table 2).

3.5. Antioxidant Status. The antioxidant effect of the HDP on tissue antioxidant markers was studied. The type 2 diabetic rats showed a significant increase in TBARS in hepatic and renal tissues $(P<.01)$. Oral administration of HDP reduced these to normal level (Figure 2$)$. There was a significant reduction $(P<.01)$ in GSH in diabetic rats. HDP administration to diabetic rats significantly increased liver and kidney GSH to near normal value (Figure 3 ). The decreased levels $(P<.01)$ of SOD and CAT in diabetic rats were found to be reverted back to near normal status after

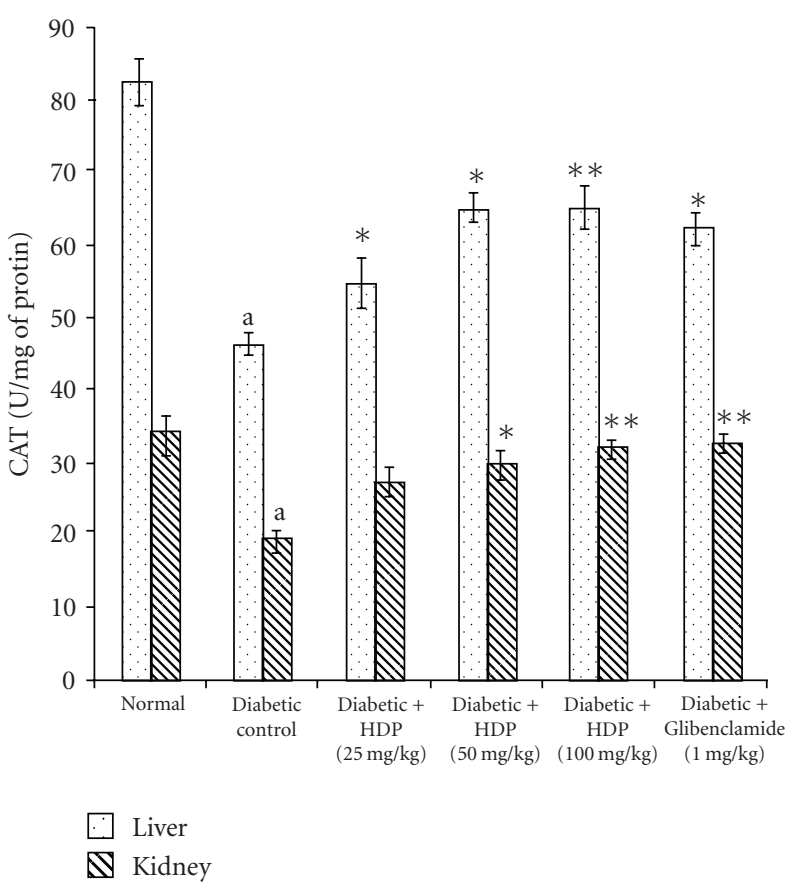

FIGURE 5: Effect of HDP on CAT of hepatic and renal tissues of type 2 diabetic rats. Data are mean \pm SE of six animals for each group. ${ }^{\text {a }} P$ $<.01$ compared with normal control group. ${ }^{*} P<.05$ compared with diabetic control group, ${ }^{* *} P<.01$ compared with diabetic control group.

the treatment of HDP (Figures 4 and 5). The HDP was found to possess antioxidant effect in a dose-dependent manner.

\section{Discussion}

When rats are injected with streptozotocin during the neonatal period, it resembles human type 2 diabetes mellitus with respect to abnormalities in insulin secretory responses [25]. In this model, mild hyperglycemia appears between 2 and 3 months of life, together with a partial deficiency in insulin [26]. In the present study, diabetes control rats exhibited significantly elevated fasting blood glucose, cholesterol and triglyceride levels as compared with normal control rats. Treatment with HDP significantly reduced fasting blood glucose and lipid levels. Maintenance of blood glucose and lipid 


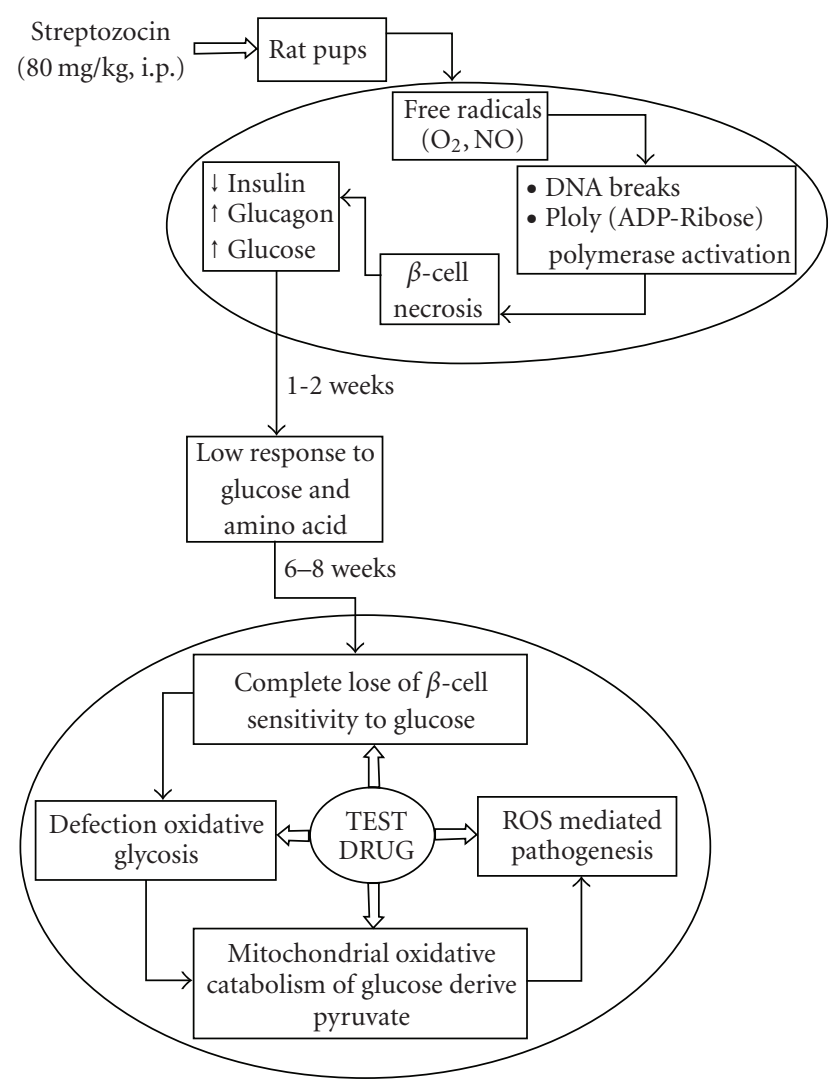

FIGURE 6: Multimodal therapeutic approach of HDP to counteract with diabetic hyperglycemia and free radical mediated pathogenesis.

profile with extract-treated rats vindicates the effectiveness of the extract against experimental type 2 diabetic rats. The significant control of plasma lipid levels suggests that the extract may produce its action by improving insulin secretion [27]. Type 2 diabetic rats exhibited significantly lower level of liver glycogen level, which was significantly reverted back near to the normal status in HDP-treated diabetic groups, may be due to reactivation of the glycogen synthase system by improving insulin secretion. Diabetes is associated with weight loss. The reversal of weight loss in extract-treated diabetic group indicates that the restorative effect of HDP may be by the reversal of gluconeogenesis and glycogenolysis [28].

An increase in hepatic and renal TBARS is an index of enhanced lipid peroxidation in diabetes, which may be due to enhance production or decrease destruction of ROS [27]. Increased TBARS in type 2 diabetic rats significantly lower in both the tissues on HDP treatment. Increased lipid peroxidation in diabetes can be due to enhanced oxidative stress in the cells as a result of depletion of antioxidant scavenger system. GSH is a major endogenous antioxidant, which counteracts free radical-mediated damage. Depletion of liver and kidney GSH levels represents enhanced oxidative stress [28]. Oral administration of HDP significantly elevated GSH level in selected tissues. SOD is an antioxidant enzyme, which reduces superoxide radicals to water and molecular oxygen while CAT reduces hydrogenperoxide [29]. Diminished activity of these antioxidant enzymes result elevation of ROS and ROS-mediated cell destruction. Reduced activities of SOD and CAT in liver and kidney were observed in diabetic rats and these were reverted to near normal status on extract treatment.

Present investigation showed that the HDP possesses considerable hypoglycemic and hypolipidemic activity in type 2 diabetic rats. The HDP also exhibited a profound antioxidant effect in diabetic rats. The multimodal therapeutic approach of HDP has been represented with the help of hypothetical diagram (Figure 6). The antioxidant defense system represents a complex network with interactions, synergy and specific tasks for a given antioxidant [30, 31]. Recent studies showed that majority of the plasma antioxidants are depleted in type 2 diabetes [32]. The depletion of antioxidants in the diabetic condition is a major cause of diabetes-related complications and onset of other disease conditions [33, 34]. Present therapeutic strategies typically attempt to relieve the clinical manifestation of diabetes and its complications [35]. The major challenge in diabetes research is to define not only the cause-effect relationship between various risk factors and complications, but also to comprehend the effects of therapeutic agents that are beneficial in the management of diabetic complications [36]. Nevertheless, the justification for the therapeutic use of antioxidants in cases of diabetes is emerging fast [37]. The quantitative estimation of total polyphenolics and flavonoids confirmed that the HDP contains substantial quantity of polyphenolics and flavonoids, which are the known antioxidant from plant sources [38]. Polyphenolics have also been reported to contribute hypoglycemic activity $[39,40]$. So, the polyphenolics-enriched fruits of $D$. peregrina may contribute in effective diabetes management in future.

\section{Acknowledgment}

The authors are thankful to Jadavpur University, Kolkata, India for providing financial support to conduct this experiment.

\section{References}

[1] S. K. Singh, P. K. Rai, D. Jaiswal, and G. Watal, "Evidencebased critical evaluation of glycemic potential of Cynodon dactylon," Evidence-Based Complementary and Alternative Medicine, vol. 5, no. 4, pp. 415-420, 2008.

[2] P. Zimmet, K. G. M. M. Alberti, and J. Shaw, "Global and societal implications of the diabetes epidemic," Nature, vol. 414, no. 6865, pp. 782-787, 2001.

[3] World Health Organization (WHO), "Diabetes Programme, 2006," October 2007, http://www.who.Int/diabetes/en/ .

[4] A. K. Mohamed, A. Bierhaus, S. Schiekofer, H. Tritschler, R. Ziegler, and P. P. Nawroth, "The role of oxidative stress and NF- $\kappa$ B activation in late diabetic complications," BioFactors, vol. 10, no. 2-3, pp. 157-167, 1999.

[5] M. Brownlee, "Advanced protein glycosylation in diabetes and aging," Annual Review of Medicine, vol. 46, pp. 223-234, 1995. 
[6] C. J. Bailey and C. Day, "Traditional plant medicines as treatments for diabetes," Diabetes Care, vol. 12, no. 8, pp. 553$564,1989$.

[7] R. A. Larson, “The antioxidants of higher plants," Phytochemistry, vol. 27, no. 4, pp. 969-978, 1988.

[8] S. Vosough-Ghanbari, R. Rahimi, S. Kharabaf et al., "Effects of Satureja khuzestanica on serum glucose, lipids and markers of oxidative stress in patients with type 2 diabetes mellitus: a double-blind randomized controlled trial," Evidence-Based Complementary and Alternative Medicine, vol. 7, no. 4, pp. 465-470, 2010.

[9] K. R. Kirtikar and B. D. Basu, Indian Medicinal Plants, B. Singh and M. P. Singh, Eds., International Book Distributors, Deharadun, India, 1975.

[10] J. Anjaria, M. Parabia, G. Bhatt, and R. Khamar, A Glossary of Selected Indigenous Medicinal Plants of India, SRISTI Innovations, Ahmedabad, India, 2nd edition, 2002.

[11] L. V. Asolkar, K. K. Kakkar, and O. J. Chakre, Second Supplement to Glossary of Indian Medicinal Plants with Active Principles Part-I (A-K), CSIR (PID) Publication, New Delhi, India, 1992.

[12] M. Kundu, S. C. Mandal, S. Dewanjee, and A. Maiti, "Hypoglycemic activity of Diospyros peregrina fruits in diabetic rats," Oriental Pharmacy and Experimental Medicine, vol. 8, pp. 279$285,2008$.

[13] S. Dewanjee, A. Maiti, and S. C. Mandal, "Antioxidant activity of the methanol extract of Diospyros peregrina fruits in alloxan induced diabetic rats," Pharmacologyonline, vol. 3, pp. 80-86, 2007.

[14] V. L. Singleton, R. M. Orthofer, and R. M. Ramuela-Raventos, "Analysis of total phenols and antioxidants and other substrates by means of Folin-Ciocalteu reagent," Methods in Enzymology, vol. 299, pp. 152-178, 1999.

[15] C.-H. Hsu, "Antioxidant activity of extract from Polygonum aviculare L," Biological Research, vol. 39, no. 2, pp. 281-288, 2006.

[16] PHS (Public Health Service), Public Health Service Policy on Humane Care and Use of Laboratory Animals, U.S. Department of Health and Human Services, Washington, DC, USA, 1986.

[17] B. Portha, L. Picolon, and G. Rosselin, "Chemical diabetes in the adult rat as the spontaneous evolution of neonatal diabetes," Diabetologia, vol. 17, pp. 371-377, 1979.

[18] A. Junod, A. E. Lambert, W. Stanffacher, and A. E. Reynold, "Diabetogenic action of streptozotocin: relationship of the dose to metabolic response," Journal of Clinical Investigation, vol. 48, pp. 2129-2139, 1969.

[19] N. Dachicourt, P. Serradas, D. Bailbé, M. Kergoat, L. Doaré, and B. Portha, "Glucagon-like peptide-1(7-36)-amide confers glucose sensitivity to previously glucose-incompetent $\beta$-cells in diabetic rats: in vivo and in vitro studies," Journal of Endocrinology, vol. 155, no. 2, pp. 369-376, 1997.

[20] C. G. Fraga, B. E. Leibovita, and A. L. Toppel, "Lipid peroxidation measured as TBARS in tissue slices: characterisation and comparison with homogenates and microsomes," Free Radical Biology and Medicine, vol. 4, pp. 155-161, 1988.

[21] G. L. Ellman, "Tissue sulphydryl groups," Archives of Biochemistry and Biophysics, vol. 82, pp. 70-77, 1959.

[22] P. Kakkar, B. Das, and P. N. Viswanathan, "A modified spectrophotometric assay of superoxide dismutase," Indian Journal of Biochemistry and Biophysics, vol. 21, no. 2, pp. 130132,1984 .

[23] A. K. Sinha, "Colorimetric assay of catalase," Analytical Biochemistry, vol. 47, no. 2, pp. 389-394, 1972.
[24] N. V. Caroll, R. W. Longley, and J. H. Roe, "The determination of glycogen in liver and muscle by use of anthron reagent," The Journal of Biological Chemistry, vol. 220, pp. 583-593, 1956.

[25] I. G. Fantus, R. Chayoth, L. O’Dea, E. B. Marliss, J.-F. Yale, and M. Grose, "Insulin binding and glucose transport in adipocytes in neonatal streptozocin-injected rat model of diabetes mellitus," Diabetes, vol. 36, no. 5, pp. 654-660, 1987.

[26] A. Barberà, J. Fernàndez-Alvarez, A. Truc, R. Gomis, and J. J. Guinovart, "Effects of Tungstate in neonatally streptozotocininduced diabetic rats: mechanism leading to normalization of glycaemia," Diabetologia, vol. 40, no. 2, pp. 143-149, 1997.

[27] A. Shirwaikar, K. Rajendran, and C. D. Kumar, "Oral antidiabetic activity of Annoa squamosa leaf alcohol extract in NIDDM rats," Pharmaceutical Biology, vol. 24, pp. 30-35, 2004.

[28] A. Griesmacher, M. Kindhauser, S. E. Andert et al., "Enhanced serum levels of thiobarbituric-acid-reactive substances in diabetes mellitus," American Journal of Medicine, vol. 98, no. 5, pp. 469-475, 1995.

[29] C. V. Anuradha and R. Selvan, "Effect of oral methionine on tissue lipid peroxidation and antioxidants in alloxan-induced diabetic rats," Journal of Nutritional Biochemistry, vol. 4, no. 4, pp. 212-217, 1993.

[30] I. S. R. Punitha, K. Rajendran, A. Shirwaikar, and A. Shirwaikar, "Alcoholic stem extract of Coscinium fenestratum regulates carbohydrate metabolism and improves antioxidant status in streptozotocin-nicotinamide induced diabetic rats," Evidence-Based Complementary and Alternative Medicine, vol. 2, no. 3, pp. 375-381, 2005.

[31] M. C. Sabu and R. Kuttan, "Antidiabetic and antioxidant activity of Terminalia belerica," Indian Journal of Experimental Biology, vol. 47, no. 4, pp. 270-275, 2009.

[32] J. M. C. Gutteridge, "Lipid peroxidation and antioxidants as biomarkers of tissue damage," Clinical Chemistry, vol. 41, no. 12, pp. 1819-1828, 1995.

[33] D. K. Arulmozhi, A. Veeranjaneyulu, and S. L. Bodhankar, "Neonatal streptozotocin-induced rat model of type 2 diabetes mellitus: a glance," Indian Journal of Pharmacology, vol. 36, no. 4, pp. 217-221, 2004.

[34] O. Said, S. Fulder, K. Khalil, H. Azaizeh, E. Kassis, and B. Saad, "Maintaining a physiological blood glucose level with 'glucolevel', a combination of four anti-diabetes plants used in the traditional Arab herbal medicine," Evidence-Based Complementary and Alternative Medicine, vol. 5, no. 4, pp. 421-428, 2008.

[35] F. J. Ruperez, D. Garcia-Martinez, B. Baena et al., “Dunaliella salina extract effect on diabetic rats: metabolic fingerprinting and target metabolite analysis," Journal of Pharmaceutical and Biomedical Analysis, vol. 49, no. 3, pp. 786-792, 2009.

[36] J. Z. Luo and L. Luo, "Ginseng on hyperglycemia: effects and mechanisms," Evidence-Based Complementary and Alternative Medicine, vol. 6, no. 4, pp. 423-427, 2009.

[37] W. Kusirisin, S. Srichairatanakool, P. Lerttrakarnnon et al., "Antioxidative activity, polyphenolic content and antiglycation effect of some Thai medicinal plants traditionally used in diabetic patients," Medicinal Chemistry, vol. 5, no. 2, pp. 139-147, 2009.

[38] S. R. Georgetti, D. I. Casagrande, V. M. Mambro, A. Azzolini, and M. J. V. Fonseca, "Evaluation of the antioxidant activity of different flavonoids by the chemiluminescence method," AAPS PharmSci, vol. 5, no. 2, pp. 1-5, 2003. 
[39] G. Klein, J. Kim, K. Himmeldirk, Y. Cao, and X. Chen, "Antidiabetes and anti-obesity activity of Lagerstroemia speciosa," Evidence-Based Complementary and Alternative Medicine, vol. 4, no. 4, pp. 401-407, 2007.

[40] M. Aslan, D. D. Orhan, N. Orhan, E. Sezik, and E. Yeşilada, "A study of antidiabetic and antioxidant effects of Helichrysum graveolens capitulums in streptozotocin-induced diabetic rats," Journal of Medicinal Food, vol. 10, pp. 396-400, 2007. 


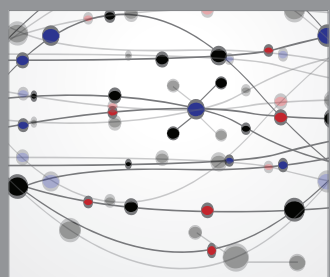

The Scientific World Journal
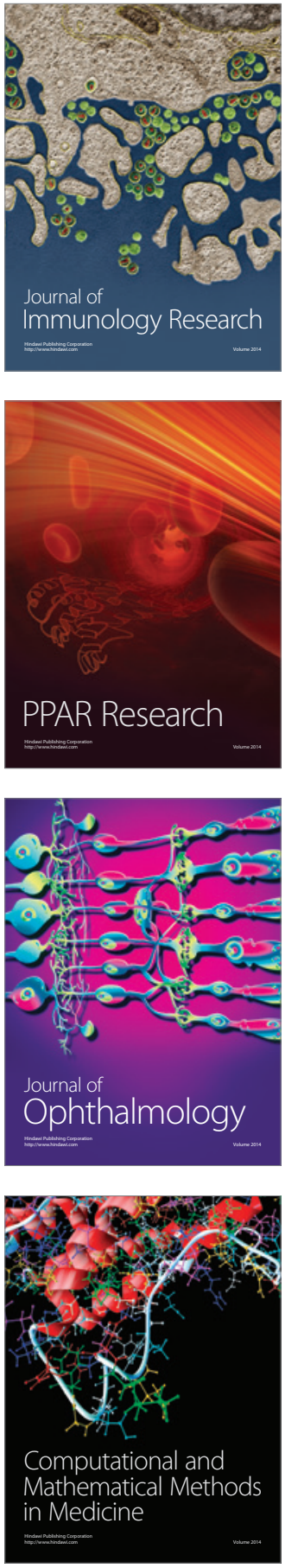

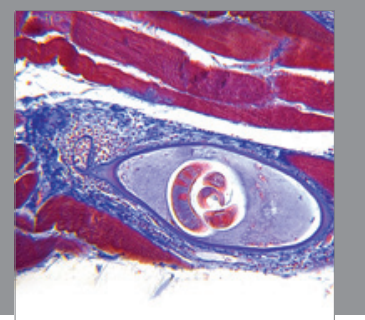

Gastroenterology

Research and Practice
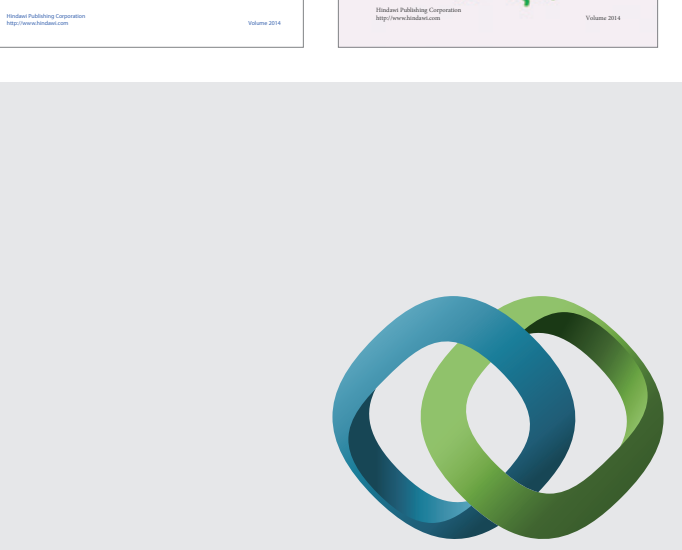

\section{Hindawi}

Submit your manuscripts at

http://www.hindawi.com
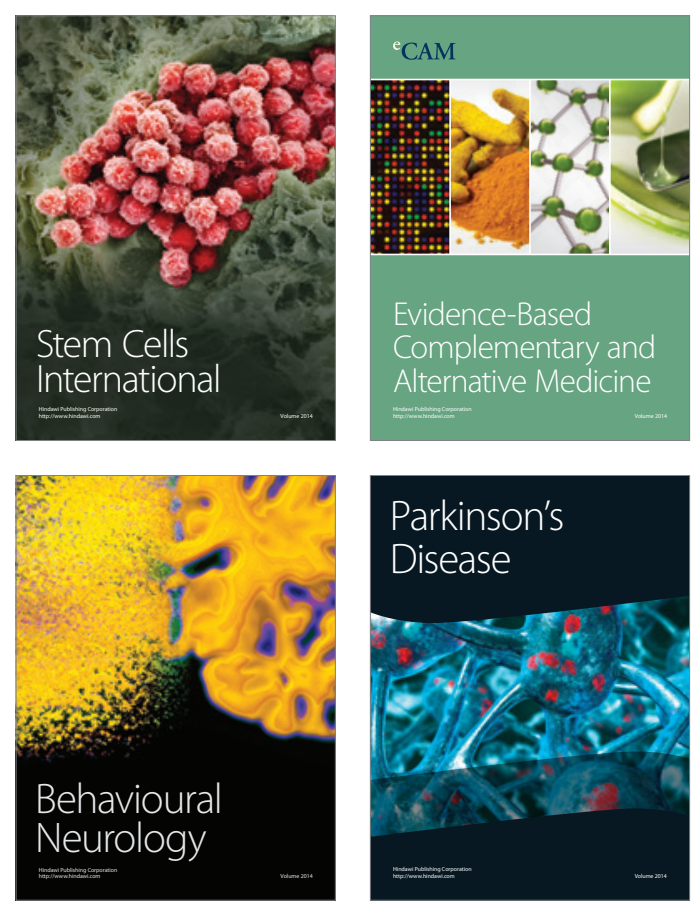

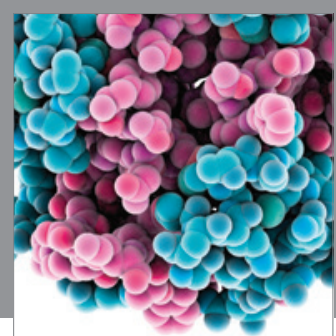

Journal of
Diabetes Research

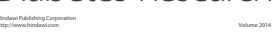

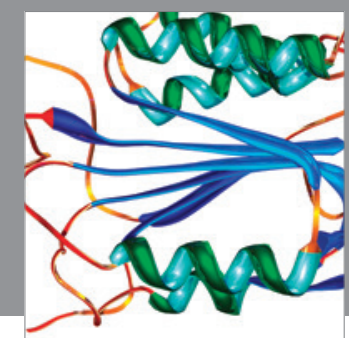

Disease Markers
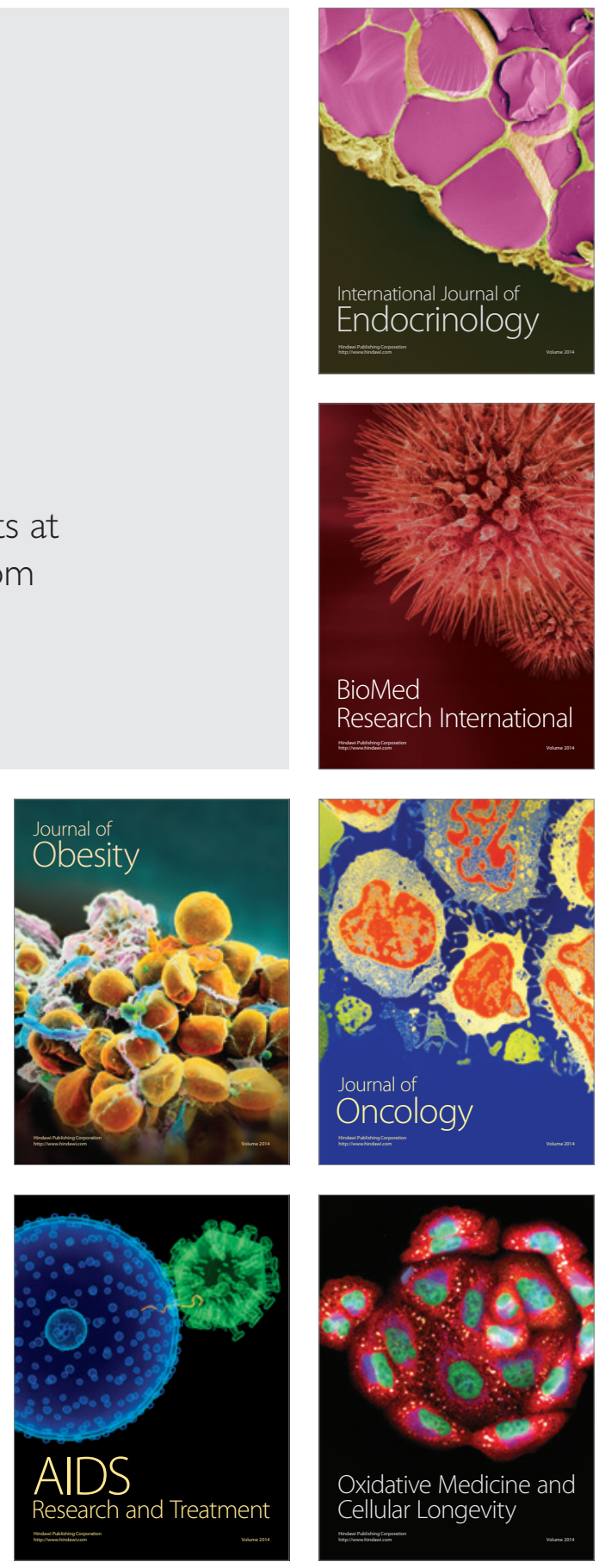